\title{
Toxinotyping of Clostridium perfringens in Poultry from Necrotic Enteritis Cases
}

\author{
Prerana Shelke ${ }^{1}$, Mrunalini Pawade ${ }^{1 *}$, Prashant Mhase ${ }^{1}$, Chandrashekhar Mote $^{2}$, Vijaysinh Lonkar ${ }^{3}$, \\ Dayaram Suryawanshi ${ }^{4}$ and Jyotika Sangle ${ }^{1}$ \\ ${ }^{1}$ Department of Veterinary Microbiology, KNP College of Veterinary Science,Shirwal, Satara, Maharashtra, INDIA \\ ${ }^{2}$ Department of Veterinary Pathology, KNP College of Veterinary Science, Shirwal, Satara, Maharashtra, INDIA \\ ${ }^{3}$ Department of Poultry Science, KNP College of Veterinary Science, Shirwal, Satara Maharashtra, INDIA \\ ${ }^{4}$ Director, Omega Laboratory, Lonand, Satara, Maharashtra, INDIA \\ *Corresponding author: M. Pawade; E-mail: mrunalinibudhe@yahoo.co.in
}

Received: 14 Aug., 2019

Revised: 20 Jan., 2020

Accepted: 25 Jan., 2020

\begin{abstract}
Clostridium perfringens is well known causative agent of necrotic enteritis in poultry and is mainly caused by Type A toxin. NetB toxin is found to be one of the newly emerging virulent toxin gene which is also responsible for necrotic enteritis. The present study was carried out to characterize and to type the different toxins associated with $C$. perfringens in NE cases of poultry. For the present study total 125 samples were collected from poultry birds, out of which 50 samples were of intestinal content from diseased birds, 50 cloacal swabs and 25 intestinal content from healthy birds. These samples were further processed for isolation, identification, and toxinotyping of Clostridium perfringens isolates. Onisolation of C. perfringens on blood agar total 43 isolates were found positive showing a pattern of double hemolysis on blood agar. The positive isolates of C. perfringens were further confirmed by using $16 \mathrm{~S}$ rRNA species specific PCR. After confirmation isolates were processed for toxinotyping mainly targeting $\mathrm{cpa}, \mathrm{cpb}$ and $\mathrm{cpb} 2$ toxins by using multiplex PCR. On toxinotyping it was found that NE in poultry birds were mainly caused by $C$. perfringens type A. On virulent gene detection of netB toxin, total 4 isolates were found positive for netB toxin. This study pointed out that $C$. perfringens type $\mathrm{A}$ is responsible for development of NE in poultry along with net $\mathrm{B}$ toxin which is a new key virulent factor. Further studies of netB toxoid and $C$. perfringens type A for vaccine production could minimize the clostridial problems in broiler farms.
\end{abstract}

Keywords: Necrotic enteritis, Clostridium perfringens, toxinotyping, poultry, netB, 16SrRNA.

Poultry production in India has taken a dramatic leap in the last four decades, emerging from an unscientific farming practice to commercial production system (Dar et al., 2017). The basic role of poultry production is turning feed stuffs into meat. Any slight alteration from the optimal condition is mostly accompanied by disruption of the growth process and all over performance. In the past, the use of antimicrobial growth promoters (AGP) in commercial poultry feed helped to control necrotic enteritis (NE) in poultry flocks. However, NE has reemerged as a significant problem in poultry production, likely as a result of national and international policies that ban or limit the use of AGP in poultry feeds. In addition, consumers preference had a large effect on bird production, and the push for poultry. Production with less medication in the diet has also had a significant effect on the increased incidence of NE in the past few years (Pavia and McElory, 2014), among these all enteric diseases are one of the most important problems in the poultry industry leading to production losses, high mortality and risk of contamination of poultry products for human consumption. Enteric disorders are frequently associated with an overgrowth of anaerobic bacteria named Clostridium perfringens.

Clostridium perfringens is a gram-positive rod and important anaerobic spore forming human and animal

How to cite this article: Shelke, P., Pawade, M., Mhase, P., Mote, C., Lonkar, V., Suryawanshi, D. and Sangle, J. (2020). Toxinotyping of Clostridium perfringens in poultry from necrotic enteritis cases. J. Anim. Res., 10(1): 149-155. 
pathogen that can produce up to 17 different toxins and enzymes. The bacterium is commonly found in a wide variety of environments, from soil to the intestinal tracts of animals and human plays a major role as a pathogen (Shojadoost et al., 2010). C. perfringens strains are classified into five toxinotypes, A to E according to the production of four major extracellular toxins namely, alpha $(\alpha)$, beta $(\beta)$, epsilon $(\varepsilon)$ and iota $(1)$, while various strains can also produce other toxins including $\beta 2$, $\operatorname{theta}(\theta)$ perfringolysin $(\mathrm{O})$, kappa $(\kappa)$, delta $(\delta), \mathrm{mu}(\mu)$, enterotoxin, necrotic enteritis B-like toxin (NetB), TpeL (toxin $C$. perfringens large cytotoxin).Type A produces $\alpha$ toxin, type $\mathrm{B}$ produces $\alpha, \beta$ and $\varepsilon$ toxins, type $\mathrm{C}$ produces $\alpha$ and $\beta$ toxins, type $\mathrm{D}$ produces $\alpha$ and $\varepsilon$ toxins and type $\mathrm{E}$ produces $\alpha$ and $\mathrm{t}$ toxins (Dar et al., 2017).

The $C$. perfringens strains that infect avian species produce many extracellular toxins; however, toxins alpha (encoded by cpa), beta (cpb), beta-2 (cpb2), enterotoxin (cpe) and netB are the most significant. Toxins beta, beta-2 and netB are thought to be pore-forming in nature, causing increased permeabilities. Toxins beta- 2 and netB may be found in several bacterial isolates and have been indicated as possible factors of pathogenesis, although incidence of these genes varies (Brady et al., 2010).

Clinical necrotic enteritis (NE) in young chickens is mainly caused by $C$. perfringens type A and, to a lesser extent, type C (Shojadoost et al., 2010). Toxin genotyping are of great importance in epidemiological studies of etiological agents and in detection of virulence factors of the pathogen

\section{MATERIALS AND METHODS}

A total of 125 samples comprising of intestinal and cloacal swabs (live birds) were collected aseptically from backyard and commercial poultry farm. Out of 125 samples collected, 75 were from healthy and 50 were from diseased bird showing signs of enteritis. Samples were collected from Pune and Satara district of Western Maharashtra. Intestinal samples were collected from suspected cases of birds with enteritis referred for post mortem cases at Department of Pathology, KNPCVS, Shirwal and from Omega laboratory, Lonand, Dist., Satara for this study. From diseased (enteritis suspected) birds, intestinal contents were collected and from healthy poultry birds, intestinal contents as well as cloacal swabs were collected. Samples comprising of cloacal swabs and intestinal contents were collected aseptically in a sterile container and quickly transported to the laboratory in icecooled containers. Processing of the collected samples were done as soon as samples received to the department.

\section{Isolation of $C$. perfringens}

All the samples received to the laboratory, were inoculated in Robertson's cooked meat media (RCMM). Inoculated $\mathrm{RCMM}$ were heated at $80^{\circ} \mathrm{C}$ for 10 minutes to destroy vegetative form of organisms, followed by anaerobic incubation using anaerobic jars with anaerogas pack at $37^{\circ} \mathrm{C}$ for $24-48$ hours. After incubation, a loopful of broth cultures were further streaked onto $5 \%$ sheep blood agar for cultivation of Clostridium perfringens and for determination of hemolytic activity of the organism. The blood agar plates were incubated anaerobically for $24 \mathrm{hrs}$ at $37^{\circ} \mathrm{C}$ (Balachandran et al., 2018).

\section{Extraction of DNA from suspected colonies}

Two to three suspected pure colonies from $5 \%$ sheep blood agar plates, showing a double hemolysis pattern were suspended in $100 \mu \mathrm{l}$ of distilled water in a $1.5 \mathrm{ml}$ microcentrifuge tube and further DNA was isolated by boiling method (Dar et al., 2017).

\section{Confirmation of $C$. perfringens by using 16S rRNA species specific gene}

The isolates were confirmed for detection of $C$. perfringens using species specific 16S rRNA gene sequences (Tonooka et al., 2005). After DNA extraction, the identity of the samples was confirmed as $C$. perfringens based on the amplification of specific 16S rRNA gene, using specific primers (Table 1). PCR was performed by preparing a final reaction volume of $20 \mu \mathrm{l}$ in $0.2 \mathrm{ml}$ thin walled PCR tubes. It was prepared by taking $3.3 \mu \mathrm{l}$ master mix supplied with Taq DNA, $\mathrm{MgCl} 2$ and dNTPs; adding $2 \mu \mathrm{l}$ each of forward and reverse primers, $2 \mu$ template DNA and 10.7 $\mu l$ nuclease free water. The reaction was carried out in a thermocycler as follows: initial denaturation of $94^{\circ} \mathrm{C}$ for 2 min, followed by 35 cycles of $94^{\circ} \mathrm{C}$ for $30 \mathrm{sec}, 56^{\circ} \mathrm{C}$ for 30 sec, $72^{\circ} \mathrm{C}$ for $1 \mathrm{~min}$ and a final extension at $72^{\circ} \mathrm{C}$ for $2 \mathrm{~min}$. 
Table 1: PCR primers used for detection of C. perfringens and its toxin cpa, cpb and cpb2 gene

\begin{tabular}{llll}
\hline Sl. No. & Targeted Gene & Oligonucleotide sequence & Amplicon size \\
\hline 1 & 16S rRNA & F: TAACCTGCCTCATAGAGT & $481 \mathrm{bp}$ \\
& & R: TTTCACATCCCACTTAATC & $324 \mathrm{bp}$ \\
2 & $\mathrm{cpa}$ & F: GCTAATGTTACTGCCGTTGA & $198 \mathrm{bp}$ \\
& & R: CCTCTGATACATCGTGTAAG & \\
& & F: GCGAATATGCTGAATCATCA & $548 \mathrm{bp}$ \\
& $\mathrm{cpb}$ & R: GCAGGAACATTAGTATATCTTC & $384 \mathrm{bp}$ \\
& & F: AAATATGATCCTAACCAACAA & R: CCAAATACTCTAATYGATGC \\
& & F: GCTGGTGCTGGAATAAATGC & \\
\hline
\end{tabular}

\section{Toxinotyping of $C$. perfringens by multiplex PCR}

For typing, all the isolates of $C$. perfringens confirmed by species specific gene were subjected for multiplex PCR (m-PCR) using toxin genes $\alpha$ (cpa), $\beta$ (cpb) and $\beta 2$ (cpb2) as referred previously by Brady et al. (2010) (cpa and cpb gene) and Dar et al., 2017 for cpb2. (Table 1). The multiplex PCR assays in this study were performed in $25 \mu \mathrm{l}$ reaction volume in Mastercycler gradient (Eppendorf AG, Germany). Three pairs of specific primers corresponding to each toxin were used to determine the presence of cpa, cpb, and cpb2 toxin genes using a multiplex PCR technique for all species specific confirmed isolates. PCR was performed by preparing a final reaction volume of 25 $\mu \mathrm{l}$ in $0.2 \mathrm{ml}$ thin walled PCR tubes. It was prepared by taking $3.5 \mu \mathrm{l}$ master mix supplied with Taq DNA, $\mathrm{MgCl}_{2}$ and dNTPs; adding $1.5 \mu \mathrm{l}$ each of forward and reverse primers, $2 \mu \mathrm{l}$ each template DNA and $10.5 \mu$ nuclease free water. Detail about primers given in table 1. Samples were subjected to $35 \mathrm{PCR}$ cycles, each consisting of Initial denaturation of $15 \mathrm{~min}$ at $95^{\circ} \mathrm{C} ; 30 \mathrm{sec}$ of denaturation at $94^{\circ} \mathrm{C} ; 90 \mathrm{sec}$ of annealing at $53^{\circ} \mathrm{C}, 90 \mathrm{sec}$ of elongation at $72^{\circ} \mathrm{C}$ and final extension of $10 \mathrm{~min}$ at $72^{\circ} \mathrm{C}$.

\section{Detection of virulent gene netB of $C$. perfringens}

For the detection of virulent gene netB all the positive isolates were subjected to Uniplex PCR (Ezatkhah et al., 2016). Details of the primers are given in Table 1 . The Uniplex PCR assays in this study were performed in 25 $\mu \mathrm{l}$ reaction volume in Mastercycler gradient (Eppendorf
AG, Germany). PCR was performed by preparing a final reaction volume of $25 \mu \mathrm{l}$ in $0.2 \mathrm{ml}$ thin walled PCR tubes. It was prepared by taking $12.5 \mu \mathrm{l}$ master mix supplied with Taq DNA, $\mathrm{MgCl}_{2}$ and dNTPs; adding $2 \mu \mathrm{l}$ each of forward and reverse primers, $3 \mu 1$ template DNA and 5.5 $\mu 1$ nuclease free water. PCR conditions were $95^{\circ} \mathrm{C}$ for 10 min, 35 cycles of $94^{\circ} \mathrm{C}$ for $30 \mathrm{sec}, 55^{\circ} \mathrm{C}$ for $30 \mathrm{~s}$ and $72^{\circ} \mathrm{C}$ for $1 \mathrm{~min}$ followed by $72^{\circ} \mathrm{C}$ for $10 \mathrm{~min}$.

\section{RESULTS AND DISCUSSION}

\section{Phenotypic identification of $C$. perfringens}

The aim of present study was toxinotyping of $C$. perfringens associated with necrotic enteritis (NE) in poultry. Out of 50 samples of NE suspected birds and 75 samples of healthy birds, 35 isolates from NE suspected birds and 08 isolates from healthy birds respectively (total $=43$ ), were characterize phenotypically as $C$. perfringens. For phenotypic characterization all the samples were inoculated in RCM, which showed heavy turbidity along with gas production in RCMM after 24-48 hrs. of incubation,turning the meat particles pink in colour along with foul odor.

RCMM along with Brain heart infusion (BHI) broth was found to be the best medium for initial isolation of $C$. perfringens as described by Malmurugan et al. (2012). Das et al. (2008) and EI-Jakee et al. (2013) used RCMM for initial isolation of $C$. perfringens from necrotic enteritis cases of poultry. 
After enrichment, samples were streaked on 5\% sheep blood agar. On 5\% sheep blood agar after incubation, grey, glistening, smooth and round colonies of 1-2 mm diameter surrounded by double zone of haemolysis, were visualized, which is a characteristic feature of $C$. perfringens. Similar types of colonies were observed by Salah-Eldin et al. (2015) and Keyburn et al. (2010) of C. perfringens on blood agar. For morphological characteristics the culture smears were prepared from the pure colonies and stained by Gram's method which revealed Gram- positive, short and plumpy rods with blunt ends which correlated well with the reports of Hafez et al. (2011) and Khairy et al. (2013).

\section{Genotypic Identification of $C$. perfringens by using species specific 16S rRNA gene}

All the total 43 phenotypically confirmed isolates were further subjected to species specific 16S rRNA gene PCR, which showed 100 percent positive towards $C$. perfringens by species specific PCR. Molecular characterization revealed that all 43 isolates were positive for C. perfringens by species specific PCR showing amplicon size of $481 \mathrm{bp}$ on $1.5 \%$ agarose gel electrophoresis (Fig. 1).

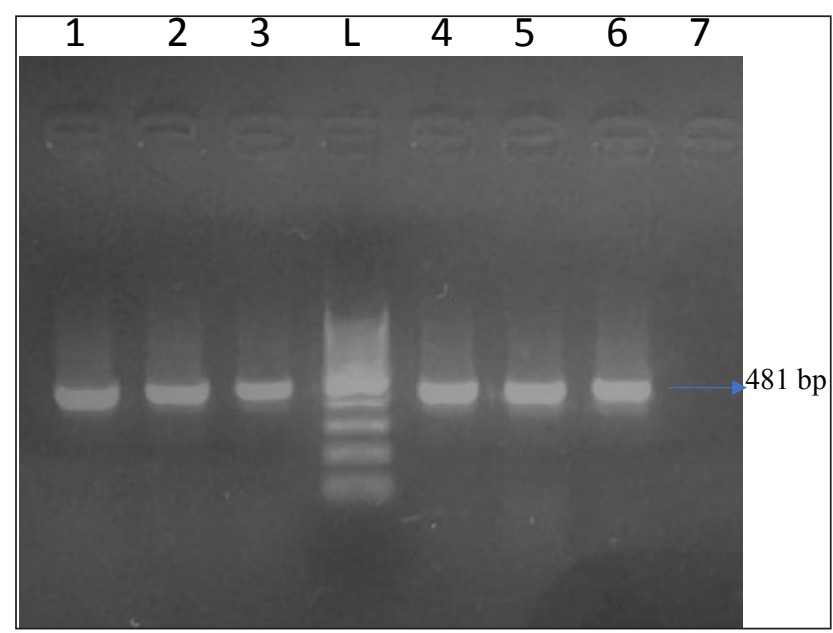

Fig. 1: Agarose gel showing $481 \mathrm{bp}$ amplicon of C. perfringens

(Species specific PCR); Lane 1,2,3,4,5,6 - Positive samples; Lane 7 - Negative samples; L - 100 bp DNA Ladder

These present findings were in close association with the results of Nyrah et al. (2017) who recorded 66 isolates from poultry and further confirmed by $16 \mathrm{~S}$ rRNA species specific PCR. Similar findings were reported by Dar et al.
(2017) who confirmed all the isolates of $C$. perfringens by species specific PCR. Nazki et al. (2017) recorded 125 $(70.62 \%)$ isolates were positive for $C$. perfringens, by using species specific primers.

\section{Toxinotyping of $C$. perfringens}

Total 43 isolates which were confirmed by $16 \mathrm{~S}$ rRNA were further processed for toxinotyping of cpa, cpb and cpb2 toxin by multiplex PCR (Fig. 2 and 3 ).

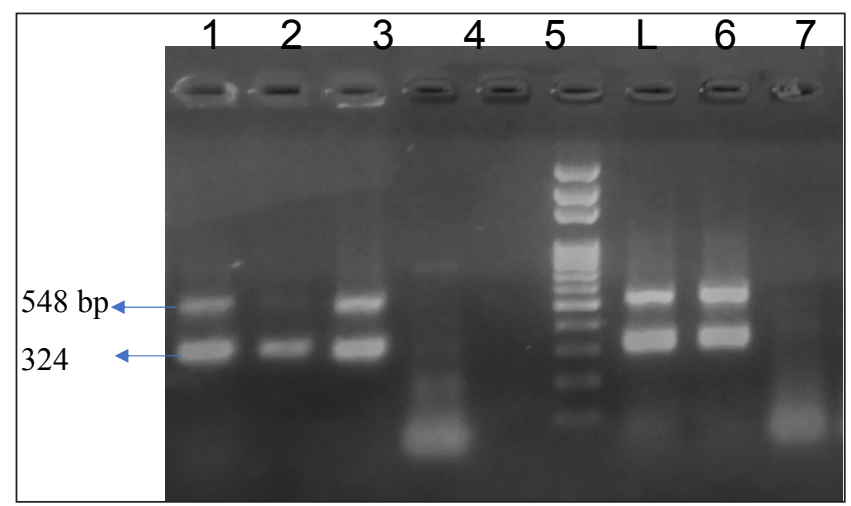

Fig. 2: Agarose gel showing $324 \mathrm{bp}$ amplicon of cpa toxin and 548 bp of cpb2 toxin

Lane 1,2,3,6,7- Positive samples for cpa and cpb2; Lane 4,5,8Negative control; L - 100 bp DNA Ladder

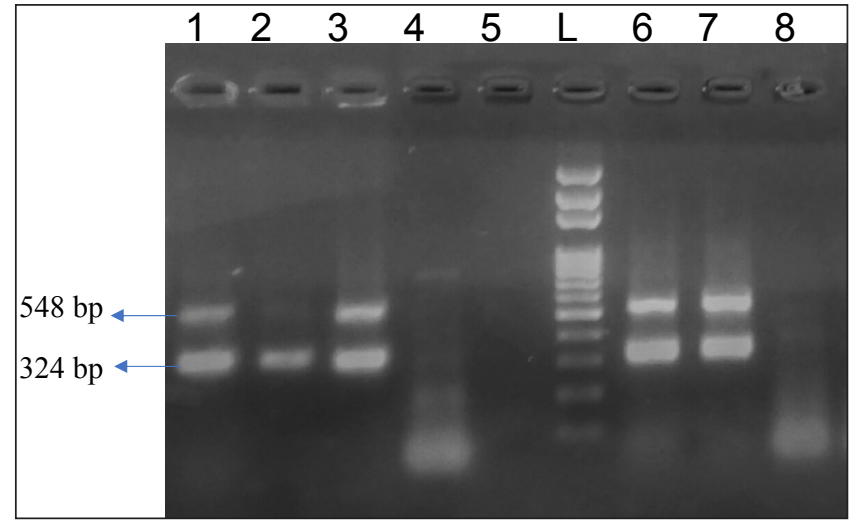

Fig. 3: Agarose gel showing $324 \mathrm{bp}$ amplicon of cpa toxin and $548 \mathrm{bp}$ of cpb2 toxin.

Lane 1,2,3,6,7- Positive samples for cpa and cpb2; Lane 4,5,8Negative control; L - 100 bp DNA Ladder

Out of total 35 isolates from NE suspected birds, 17 (48.57\%) isolates showed cpa toxin, 12 (34.28\%) isolates 
showed cpb toxin, 06 (13.95\%) isolates were positive for cpb2 toxin. Among this, 06 (13.95\%) isolates carried both the gene cpa and cpb2. Total 08 isolates from healthy birds were found positive for $C$. perfringens, out of which cpa toxin was detected in 50 percent of isolates while, cpb and cpb2 were found negative. On toxinotyping of the isolates in different types, it was seen that, out of 43 isolates, $27(62.79 \%)$ isolates belonged to C. perfringens type A and $12(27.90 \%)$ isolates belonged to $C$. perfringens type C. Toxin cpa (alpha) has been indicated as a main virulence factor for the development of NE in poultry and this toxin hydrolyses phospholipids and promotes cellular membrane disorganization which leads to destruction of intestinal mucosa. Nyrah et al. (2017) detected total 66 isolates of C. perfringens and showed 100 percent positivity towards cpa toxin while 13 isolates $(19.69 \%)$ showed positivity for cpb2 toxins. Recently, it was speculated that cpb2 positive C. perfringens may cause focal duodenal necrosis in egglaying chickens (França et al., 2016). The results of cpb2 in their study was in agreement with the present findings with similar agreement. Park et al. (2015) and Balchandran et al. (2018) recorded 100 percent prevalence of cpa toxin in the isolates of $C$. perfringens from NE cases while Rasool et al. (2017) reported 86.4 percent prevalence of cpa gene, but the prevalence of cpa gene in the present study was recorded less as compared to other studies. The possibility of the same may be due to the presence of other toxin gene which were prominently expressed and reduced the expression of the cpa gene.

Isolates carrying both the gene i.e. cpa and cpb2 were recorded in the present study, the findings of which was similar to the findings of Guran et al. (2013) and Datta et al. (2014) who found cpa and cpb2 with 2.1 percent and 33.3 percent prevalence rate, respectively. Toxin $\mathrm{cpb}$ (betatoxin) is a highly trypsin-sensitive protein that causes mucosal necrosis and possibly central nervous signs observed in domestic animals. It is responsible for the diseases caused by $C$. perfringens type $\mathrm{C}$ which causes necrotic enteritis in fowls.

\section{Detection of virulent gene netB of $C$. perfringens}

Recently, C. perfringens strains producing netB toxin have been considered as the definitive cause of NE in chickens (To et al., 2017). In present study, total 04 (11.42\%) isolates showed positivity towards netB out of 35 isolates from diseased birds (Fig. 4). None of isolates were positive for netB from healthy birds. NetB showed overall 9.30 percent prevalence from 43 isolates. These findings were in correlation with Lyhs et al. (2013) reported that the netB was identified in 6.6 percent from $C$. perfringens strains which were isolated from NE cases in turkeys. Tolooe et al. (2011) who reported, 52.8 percent prevalence of netB from diseased birds and none from healthy birds.

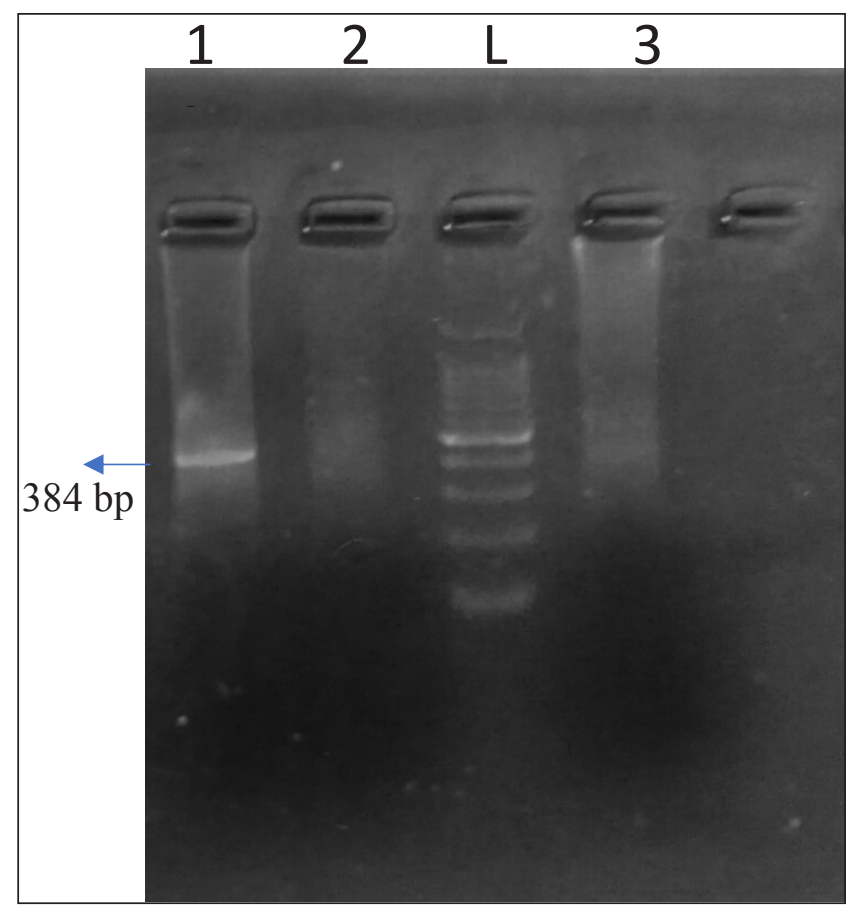

Fig. 4. Agarose gel showing $384 \mathrm{bp}$ amplicon of netB gene

Lane 1 - Positive samples; L- 100 bp DNA Ladder

Ezatkhah and associates (2016) reported netB gene for the first time at a low incidence $(7.77 \%)$ in chickens with $\mathrm{NE}$ in organic broiler farms and detected 17.98 percent prevalence by PCR. Keyburn et al. (2009) studied various $C$. perfringens isolates from NE- positive and NE- negative flocks from three continents and found 70 percent and 3.6 percent netB positive isolates, respectively. Further studies suggest that, potentially virulent toxins cpb2 along with netB could contribute to disease effects in C. perfringens isolates (Keyburn et al. 2008). Gaucher et al. (2017) reported an increase in the proportion of $C$. perfringens strains harboring the $\mathrm{cpb} 2$ gene and the netB 
gene. A possible explanation could be that netB is easily transferred between several $C$. perfringens genotypes, thus increasing their virulence (Johansson et al., 2009). NetB is involved in virulence and is a secreted protein that is readily accessible to the host immune system, and this represents a promising target for vaccine development (Keyburn et al. 2010). Confirmation of the role of netB in disease came from the finding that most necrotic enteritis outbreak strains carry the netB gene, whereas nonnecrotic enteritis derived $C$. perfringens isolates lack this gene (Keyburn et al., 2008; Keyburn et al., 2010). Present study focused on targeting the netB toxin which is one of the virulent gene detected in NE disease from poultry. Toxin netB is produced only when the $C$. perfringens concentration is high and sufficient damage is caused to host cell (Timbermont et al. 2011).

\section{CONCLUSION}

Isolation and identification of Clostridium perfringens were done from NE cases as well as from healthy birds. The overall incidence of necrotic enteritis due to $C$. perfringens was found to be 34.4 percent. 16S rRNA PCR can be used as one of the confirmatory tests for detection of $C$. perfringens from NE cases. Most of the isolates of $C$. perfringens carried the toxin gene cpa (alpha), followed by $\mathrm{cpb}$ (beta) and $\mathrm{cpb} 2$. Theoccurrence of $C$. perfringens type A more predominant than $C$. perfringens type $\mathrm{C}$ among the NE cases of poultry birds. In the present study, netB which is one of the key virulent pore forming toxin of $C$. perfringens, was detected in 9.3 percent among the NE affected poultry birds. Further studies shall be designed to know the role of the netB toxin as well as the different toxins associated with necrotic enteritis and which could be useful in future for development of vaccines.

\section{Acknowledgments}

I would like to thank my institute, Krantisinh Nana Patil College of Veterinary Science, Shirwal for their financial supports.

\section{REFERENCES}

Balachandran, P., Srinivasan, P., Balasubramaniam, GA., Sivaseelan, S. and Murthy, T.R.G.K. 2018. Prevalence and predisposing factors in spontaneous cases of necrotic enteritis in cage reared commercial layer chicken. Adv. Anim. Vet. Sci., 6(3): 113-120.

Bergey's Manual of Systemic Bacteriology, 1986.

Brady, J., J.D. Hernandez-Doria, C. Bennett, W. Guenter, J. D. House and Rodriguez-Lecompte. J.C. 2010. Toxinotyping of necrotic enteritis-producing and commensal isolates of Clostridium perfringens from chickens fed organic diets. Avian Patho., 39(6): 475-481.

Dar, P.S., Wani,S.A., Wani,A.H., I. Hussain, R. Maqbool.,Ganaie, M.Y., Kashoo, Z.A. and Qureshi, S. 2017. Isolation, identification and molecular characterization of Clostridium perfringens from poultry in Kashmir valley, India. J. Entomol. Zoo. Stud., 5(5): 409-414.

Datta, S., Rakha, N.K., Narang,G., Arora, D. and Mahajan, N.K. 2014. Prevalence of $\alpha, \beta$ and netb toxin producing strains of Clostridium perfringens in broiler chickens in Haryana. Haryana Vet., 53(1): 39-42.

EI-Jakee, J., N.S. Ata, M.A. El Shabrawy, A.S.M. Abu Elnaga, R.H. Hedia, Shawky, N.M. and Shawky, H.M. 2013. Characterization of Clostridium perfringens isolated from Poultry. Global Veterinaria., 11(1): 88-94.

Ezatkhah, M., Alimolaei, M. and Shahdadnejad, N. 2016. The Prevalence of netB Gene in isolated Clostridium perfringens From Organic Broiler Farms Suspected to Necrotic Enteritis. Int.J. Enteric Pathog., 4(3): e35667.

França, M., M.A. Barrios, L. Stabler, G. Zavala, H.L. Shivaprasad, M. D. Lee, Villegas, A.M. and Uzal, F.A. 2016. Association of beta2-positive Clostridium perfringens type A with focal duodenal necrosis in egg-laying chickens in the United States. Avian Dis., 60: 43-49.

Gaucher, M.L, Perron, G.G., J. Arsenault, A. Letellier, M. Boulianne and Quessy, S. 2017. Recurring Necrotic Enteritis Outbreaks in Commercial Broiler Chicken Flocks Strongly Influence Toxin Gene Carriage and Species Richness in the Resident Clostridium perfringens Population. Front Microbiol., 8: 881.

Guran, H. S. and Oksuztep, G. 2013. Detection and typing of Clostridium perfringens from retail chicken meat parts. Lett. Appl. Microbiol., 57: 7782.

Hafez Mohamed Hafez. 2011. Enteric Diseases of Poultry with Special Attention to Clostridium perfringens. Pak. Vet. J., 31(3): 175-184.

Johansson A., Aspán A., Kaldhusdal M. and Engström, B. 2009. Genetic diversity and prevalence of in isolated from a broiler flock affected by mild necrotic enteritis. Vet. Microbiol., 144(1-2): 87.

Keyburn, A.L., J.D. Boyce, P. Vaz, T.L. Bannam and Ford, M.E. 2008. NetB, a new toxin that is associated with avian necrotic enteritis caused by Clostridium perfringens. PLoS Pathol., 4(2): e26. 
Keyburn, A.L., T.L. Bannam, Moore, R.J. and Rood, J.I. 2010. NetB, Pore-Forming Toxin from Necrotic Enteritis Strains of Clostridium perfringens. Toxins (Basel), 2(7): 1913-1927.

Keyburn, A., X. Yan, B. Trudi, F. Immerse, Rood, J.L. and Moore, R.J. 2009. Association between avian necrotic enteritis and Clostridium perfringens strains expressing NetB toxin. Vet. Res., 41: 21.

Khairy, E.A, S.M. Dorgham, M.A. Bakry and Hakim, A.S. 2013. Molecular Diversity of Alpha Toxin Produced by Clostridium perfringens Strains Causing Avian Necrotic Enteritis. World Appl. Sci. J., 21(1): 15-20.

Lyhs, U. 2013. Characterization of Clostridium perfringens isolates from healthy turkeys and from turkeys with necrotic enteritis. Poult. Sci., 92(7): 1750-1757.

Malmarugan, S., Boobalan, A. and Dorairajan, N. 2012. Necrotic Enteritis in Broiler and Layer Farms in Tamil Nadu, India. IJAVMS., 6(4): 241-249.

Nyrah, Q., Wani, S.A., Nazir, N., Rasool, S., Beigh, Q., Kashoo, Z.A., Hussain, I., Qureshi, S. and Ali, R. 2017. Clostridium perfringens Type A from Broiler Chicken with Necrotic Enteritis in Kashmir Valley. India. Int. J. Curr. Microbiol. App. Sci., 6(12): 2443-2453.

Paiva, D. and McElroy, A. 2014. Necrotic enteritis: Applications for the poultry industry. J. Appl. Poult. Res., 23: 557566.2014

Park, J.Y., S. Kim, J.Y. Oh, H.R. Kim, J.H. Lee, and Kwon, Y.K. 2015. Characterization of Clostridium perfringens isolates obtained from 2010 to 2012 from chickens with necrotic enteritis in Korea. Poult. Sci. Association In., 94: 1158- 1164.
Rasool, S., I. Hussain, S.A. Wani, Z.A. Kashoo, Q. Beigh, Q. Nyrah, N. Nazir, T. Hussain, A.H. Wani and Qureshi, S. 2017. Molecular Typing of Clostridium perfringens Isolates from Faecal Samples of Healthy and Diarrheic Sheep and Goats in Kashmir, India. Int. J. Curr. Microbiol. App. Sci., 6(10): 3174-3184

Salah-Eldin A. E., Fawzy E. H., Aboelmagd B. A., Ragab E. A. and Shaimaa B.2015. Clinical and Laboratory Studies on Chicken Isolates of Clostridium Perfringens in El-Behera, Egypt. J. World's Poult. Res. 5(2): 21-28.

Shojadoost, B., S. M. Peighambari and Nikpiran.2010 Isolation, identification, and antimicrobial susceptibility of Clostridium perfringens isolates from acute necrotic enteritis of broiler chickens. Int. J. Vet. Res.,4(3): 147-151.

Timbermont, L., F. Haesebrouck, R. Ducatelle and F. Immerseel.2011. Necrotic enteritis in broilers: an updated review on the pathogenesis. Cavp.0025.

To, h., T. Suzuki,, F. Kawahara, K. Uetsuka, S. Nagai and T. Nunoya.2017. Experimental induction of necrotic enteritis in chickens by a netB-positive Japanese isolate of Clostridium perfringens. J. Vet. Med. Sci.,79(2): 350- 358.

Tolooe, A., B. Shojadoost and SM. Peighambari.2011.Molecular detection and characterization of cpb2 gene in Clostridium perfringens isolates from healthy and diseased chickens. $J$. Venom.Anim. Toxins Incl. Trop.Dis.,17:59-65.

Tonooka T., Sakata S., Kitahara M., Hanai M., Ishizeki S., Takada M., Sakamoto M. and Benno Y. 2005. Detection and quantification of four species of the genus Clostridium in infants feces. Microbiol.Immunol.,49(11): 987-992. 
